\title{
Sudden infant death syndrome and the diaphragm: Is there a
} \section{link?}

(c) The Author(s) 2021

Pediatric Research (2022) 91:1015-1016; https://doi.org/10.1038/s41390021-01640-1

An April 6 correspondence in Pediatric Research draws attention to the fact that from over 12,500 sudden infant death syndrome (SIDS) articles on PubMed, only 59 focus on the diaphragm. ${ }^{1}$ The existing research offers no compelling reasons to exclude the diaphragm from SIDS research. Rather, the question arises: Is there evidence to suggest that the diaphragm should be investigated? In this context, at least seven research areas warrant our attention:

1. Pathogenic gene variants of SCN4A that encode for NaV1.4, a skeletal muscle voltage-gated sodium channel that is crucial for the generation of action potentials and excitation of muscle, are overrepresented in infants who died of SIDS compared with ethnically matched controls. These functionally disruptive SCN4A variants can impair the ability of respiratory muscles to respond to hypoxia. ${ }^{2}$

2. Elevated levels of vascular endothelial growth factor in the cerebrospinal fluid of SIDS infants indicate that they experience one or more hypoxic events over several hours to days before death. ${ }^{3}$ Hypoxia exacerbates diaphragm and abdominal muscle fatigability and can impair the diaphragm's ability to generate force. ${ }^{4}$

3. There is a strong correlation between SIDS and nonlethal infections. It is well known that infections can produce severe respiratory muscle weakness in adults, which is a major contributor to respiratory failure. Infections can reduce the diaphragm's ability to generate force by as much as $50 \%$ in $24 \mathrm{~h}^{5}$

4. The prone sleeping position is an important risk factor for SIDS. For an infant, the prone position significantly increases the work of breathing and decreases respiratory muscle endurance. $^{6}$

5. Hyperthermia is independently associated with an increased risk of SIDS as the 1990 Lancet editorial Prone, hot, and dead explains. ${ }^{7}$ It is well known that hyperthermia increases the workload of the respiratory muscles. ${ }^{8}$

6. SIDS is associated with rapid eye movement (REM) sleep as the original names of the syndrome, cot and crib-death, suggest. Intercostal muscles show both phasic and tonic inhibition during REM sleep that renders them largely or totally inactive. The chest wall muscles are critical for ventilation in the infant with a pliable chest wall, and loss of muscle tone increases the diaphragm's workload. ${ }^{9}$

7. The Collaborative Home Infant Monitoring Evaluation study that entailed the analysis of over $700,000 \mathrm{~h}$ of home monitoring of infants 6 months after birth, concluded: "We determined that events previously described as 'pathologic' are actually quite common, even in healthy term infants." ${ }^{10}$
The study monitored apnea, bradycardia, and hypoxemia, indicating that serious respiratory events are relatively common in young infants.

Considering that SIDS likely has a respiratory origin, that diaphragm failure is a well-known terminal event in adults, and the evidence discussed above, the possible link between diaphragm failure and SIDS should be investigated.

\section{DISCLAIMER}

The work is original, it is not previously published, and is not submitted for publication or consideration elsewhere.

\author{
Pontus M. Siren ${ }^{1 凶}$ \\ ${ }^{1}$ Independent Researcher, Crassier, Switzerland. \\ 凶email: pontusmax@hotmail.com
}

\section{REFERENCES}

1. Siren, P. Blind spot. Pediatr. Res. (2021). https://doi.org/10.1038/s41390-02101508-4 [Online ahead of print].

2. Männikkö, R. et al. Dysfunction of NaV1.4, a skeletal muscle voltage-gated sodium channel, in sudden infant death syndrome: a case-control study. Lancet 391, 1483-1492 (2018).

3. Kimberly, J. et al. Vascular endothelial growth factor in the cerebrospinal fluid of infants who died of sudden infant death syndrome: evidence for antecedent hypoxia. Pediatrics 111, 358-63 (2003).

4. Siren, P. SIDS-CDF hypothesis revisited: explaining hypoxia in SIDS. Ups. J. Med. Sci. 121, 199-201 (2016).

5. Siren, P. \& Siren, M. J. Critical diaphragm failure in sudden infant death syndrome. Ups. J. Med. Sci. 116, 115-23 (2011).

6. Rehan, V. et al. Effects of the supine and prone position on diaphragm thickness in healthy term infants. Arch. Dis. Child 83, 234-238 (2000).

7. Editorial, Prone, hot, and dead. Lancet 336, 1104 (1990).

8. Siren, P. SIDS-CDF hypothesis revisited: cause vs. contributing factors. Front. Neurol. 7, 244 (2016).

9. Davis, G. \& Bureau, M. Pulmonary and chest wall mechanics in the control of respiration in the newborn. Clin. Perinatol. 14, 551-79 (1987).

10. Ramanathan, R. et al. Cardiorespiratory events recorded on home monitors: comparison of healthy infants with those at increased risk for SIDS. JAMA 285, 2199-207 (2001).

\section{ADDITIONAL INFORMATION}

Correspondence and requests for materials should be addressed to P.M.S.

Reprints and permission information is available at http://www.nature.com/ reprints

Publisher's note Springer Nature remains neutral with regard to jurisdictional claims in published maps and institutional affiliations. 
(c) (1) Open Access This article is licensed under a Creative Commons Attribution 4.0 International License, which permits use, sharing, adaptation, distribution and reproduction in any medium or format, as long as you give appropriate credit to the original author(s) and the source, provide a link to the Creative Commons license, and indicate if changes were made. The images or other third party material in this article are included in the article's Creative Commons license, unless indicated otherwise in a credit line to the material. If material is not included in the article's Creative Commons license and your intended use is not permitted by statutory regulation or exceeds the permitted use, you will need to obtain permission directly from the copyright holder. To view a copy of this license, visit http://creativecommons. org/licenses/by/4.0/.

() The Author(s) 2021 